\title{
Pengaruh Celebrity Endorsement dan Perceived Advertising Value Terhadap Keputusan Pembelian di Fore Coffee
}

\author{
Leonardo, Rezi Erdiansyah \\ leleeoolung@gmail.com,rezie@fikom.untar.ac.id \\ Fakultas Ilmu Komunikasi Tarumanagara
}

\begin{abstract}
The purpose of this research is to determine the effect of celebrity endorsement and perceived advertising value on purchase decisions at Fore Coffee. The author conducted this research by distributing the questionnaries to a sample of 170 people who have made a purchase at Fore Coffee in Jakarta. The questionnaries distributed through google form. Data analysis techniques using SEM through the LISREL 8.70 software. The results of this study found that both dependent variables namely celebrity endorsement and perceived advertising value had a significant effect on purchase decisions. From the two dependent variables, perceived advertising value has more effects than the celebrity endorsement for purchasing decisions at Fore Coffee.
\end{abstract}

Keywords: advertising, celebrity endorsement, perceived advertising value, purchase decisions

\begin{abstract}
Abstrak
Penelitian ini bertujuan untuk mengetahui pengaruh penggunaan celebrity endorsement dan perceived advertising value terhadap keputusan pembelian di Fore Coffee. Penulis melaksanakan penelitian ini dengan menyebarkan kuesioner kepada sampel sebanyak 170 orang konsumen yang pernah melakukan pembelian di Fore Coffee di Jakarta. Kuesioner disebarkan melalui google form. Teknik analisis data menggunakan SEM melalui aplikasi LISREL 8.70. Penelitian ini memperoleh hasil bahwa kedua variabel dependen yaitu celebrity endorsement dan perceived advertising value memberikan pengaruh yang signifikan terhadap keputusan pembelian. Dari kedua variabel dependen tersebut, perceived advertising value berpengaruh lebih besar disbanding variabel celebrity endorsement terhadap keputusan pembelian di Fore Coffee.
\end{abstract}

Kata Kunci: advertising, celebrity endorsement, keputusan pembelian, perceived advertising value.

\section{Pendahuluan}

Dalam era digital yang sedang berkembang pada saat ini, persaingan dalam berbisnis menjadi semakin ketat, perusahaan perlu melakukan inovasi yang memicu bertumbuhnya jumlah pembelian. Keputusan pembelian merupakan keputusan untuk membeli, berasal dari sejumlah keputusan yang ada dalam diri seseorang (Mulyawati et at., 2015). Keputusan pembelian dapat diartikan sebagai sebuah konsep dalam perilaku konsumen mengambil keputusan untuk bertindak maupun melakukan pembelian ataupun memanfaatkan jasa atau produk yang dipilihnya (Balawera, 2013). Menurut Wijayanti (2008) pada umumnya keputusan pembelian merupakan pilihan antara dua atau lebih dari alternatif yang tersedia. 
Banyak faktor yang dapat mempengaruhi meningkatnya keputusan pembelian dalam perusahaan. Menurut Khan dan Lodhi (2016) salah satu faktor yang mempengaruhi keputusan pembelian adalah peran dari celebrity endorsement, dimana pemasaran menggunakan celebrity endorsement terbukti dari penelitian yang telah dilakukan olehnya lebih efektif dibandingkan dengan tidak menggunakan celebrity endorsement. Efek dari celebrity endorser sebagai salah satu alat promosi bagi perusahaan juga memberikan hasil yang positif dan signifikan terhadap keputusan pembelian (Ha dan Lam, 2017).

Periklanan atau advertising merupakan jenis komunikasi non - personal dan komersil, arti dari kata "non-personal" berarti iklan melibatkan media massa yang dapat mengirimkan pesan kepada sejumlah besar kelompok individu pada saat yang bersamaan (Suhandang, 2010; Dennyka dan Erdiansyah 2017). Kotler (dalam Mulyana, 2014) mengungkapkan bahwa periklanan merupakan kegiatan promosi barang, ide dan jasa yang berasal dari suatu sponsor dan memerlukan biaya. Iklan dinilai berhasil apabila dapat menarik target konsumen yang ada, sehingga ada kemungkinan bahwa konsumen tersebut akan menggunakan produk yang sedang diiklankan.

Seperti yang menjadi pilihan oleh Fore Coffee, Fore Coffee menggunakan media iklan di media jejaring sosial internet seperti instagram, youtube. Iklan yang dipilih oleh Fore Coffee berupa jenis iklan pop up. Menurut Ammarie dan Nurfebiaraning (2018) yaitu jenis iklan yang muncul secara tiba-tiba pada saat konsumen sedang menggunakan aplikasinya. Menurut Gaber et al., (2019) perceived advertising value atau nilai iklan yang dirasakan oleh konsumen dapat memberikan citra kepada perusahaan, bagaimana para konsumen memandang sebuah merek. Reaksi konsumen setelah melihat sebuah iklan dapat bermacam-macam, hal ini penting karena dapat mempengaruhi sikap konsumen tersebut kedepannya. Watie (2012) berpendapat bahwa dari itu iklan sebaiknya dibuat semenarik mungkin sehingga memanjakan para konsumen, bukan melainkan membuat jengkel yang melihatnya.

Perusahaan Fore Coffee baru berdiri sekitar satu tahun yang lalu tepatnya pada Agustus 2018, Fore Coffee muncul pada saat perusahaan industri kopi di Indonesia sedang banyak dipilih oleh pengusaha. Selain untuk meramaikan industri yang sedang menjadi pilihan utama, Fore Coffee juga bertujuan untuk berkontribusi untuk pertumbuhan perekonomian di Indonesia. Fore Coffee menjadi salah satu perusahaan start-up di bidang gerai kopi yang berkembang sangat pesat, dimulai dari cepat dibuka gerai baru di Jakarta, hingga banyaknya iklan yang digunakan oleh Fore Coffee untuk memperkenalkan produknya kepada konsumen.

Berdasarkan uraian di atas maka peneliti memiliki ketertarikan untuk melakukan penelitian yang berkaitan dengan celebrity endorsement dan perceived advertising value yang mempengaruhi keputusan pembelian di Fore Coffe Jakarta.

\section{Celebrity Endorsement}

Adam dan Hussain (2017) celebrity endorsement merupakan industri yang berkembang sangat pesat pada saat ini, di era modernisasi ini dunia periklanan telah berubah dari cara terdahulu menuju metode yang lebih modern. Dalam upaya mewujudkan kesuksesan suatu strategi, kini digunakan celebrity yang terkenal demi upaya memberikan dampak terhadap keputusan pembelian konsumen. Pelaku dalam celebrity endorsement biasa disebut endorser. Shimp (dalam Mulyawati, 2015:2) mengatakan celebrity endorsement merupakan salah satu pilihan yang digunakan 
untuk mengiklankan suatu produk dengan memanfaatkan seseorang yang memiliki ketenaran atau dikenal di kalangan masyarakat luas sehingga dapat membantu produk tersebut agar diketahui orang banyak. Ha dan Lam (2017:66) menyatakan celebrity endorsement memiliki beberapa dimensi yaitu celebrity trustworthiness, celebrity expertise, celebrity attractiveness, celebrity similarity, celebrity liking, celebrity familiarity, dan celebrity match-up congruence with the brand/product.

\section{Perceived Advertising Value}

Nilai dalam sebuah iklan didefinisikan sebagai evaluasi dari nilai dan utilitas melakukan iklan kepada konsumen (Ducoffe dalam Sulistiowaty et al.,) Dalam penelitian Zeng et al., (2009) mengatakan bahwa iklan yang bersifat informatif dapat memberikan nilai lebih terhadap iklan tersebut, dimana pengetahuan yang didapat oleh konsumen akan menghasilkan respon yang positif karena konsumen mendapatkan nilai informasi dan juga nilai dari produk tersebut. Menurut Brackett dan Carr (dalam Gaber et al., 2019) memberikan gambaran mengenai dimensi dari pesan dalam iklan yaitu credibility, irritation, informativeness, entertainment.

\section{Keputusan Pembelian}

Kotler dan Keller (2012:167) mengatakan keputusan pembelian adalah keputusan dalam tidak meneruskan atau meneruskan pembelian. Suharno (2010:96) menyatakan bahwa keputusan pembelian adalah situasi dimana konsumen sudah menentukan pilihannya dan melakukan pembelian produk, serta menggunakannya. Proses pengambilan keputusan yang dilakukan oleh seorang individu terhadap suatu produk dimulai karena adanya kebutuhan dan keinginan yang telah dirasakan sebelumnya. Menurut Kotler (2012:234) proses keputusan pembelian konsumen terdiri dari lima dimensi yakni pengenalan masalah, pencarian informasi, evaluasi alternatif, keputusan pembelian, dan perilaku pasca pembelian.

\section{Hipotesis}

$\mathrm{H}_{1}$ : Celebrity endorsement yang memiliki pengaruh yang signifikan terhadap keputusan pembelian.

$\mathrm{H}_{2}$ : Perceived advertising value memiliki pengaruh yang signifikan terhadap keputusan pembelian.

\section{Metode Penelitian}

Dalam penelitian ini, peneliti menggunakan metode penelitian kuantitatif. Penelitian kuantitatif adalah metode penelitian yang berfungsi untuk meneliti suatu sampel atau populasi, teknik pengumpulan sampel biasanya secara acak, analisis data bersifat statistik agar hipotesis yang ditetapkan dapat teruji (Sugiyono, 2016).

Penelitian ini menggunakan 34 indikator pernyataan yang diolah sesuai dengan dimensi yang membentuk masing-masing variabel. Terdapat tiga variabel dalam penelitian ini, pertama adalah celebrity endorsement yang di dalamnya terdapat 16 indikator dalam membentuk dimensinya. Selanjutnya perceived advertising value memiliki 8 indikator yang membentuk dimensinya. Variabel terakhir yaitu keputusan pembelian yang di dalamnya terdapat 10 indikator yang membentuknya. 
Dalam penelitian ini penulis menggunakan program statistical product and service solutions (SPSS) versi 15, program ini membantu penulis untuk memperoleh karakteristik data responden, uji reliabilitas dan uji validitas. Dalam pengolahan data penulis menggunakan software Lisrel 8.70 sebagai perangkat lunak dari structural equation model (SEM).

\section{Hasil Temuan dan Diskusi}

Dalam penelitian ini penulis menyebarkan kuesioner kepada 170 responden yang pernah membeli minuman Fore Coffee. Berdasarkan jenis kelamin, jumlah responden perempuan dalam penelitian ini lebih banyak yaitu 107 orang atau dengan persentase $62.9 \%$ dan laki-laki sebanyak 63 orang atau dengan persentase $37.1 \%$. Berdasarkan data yang diperoleh dari 170 responden, sebanyak 34 responden setara $20 \%$ yang berusia $\leq 20$ tahun, sebanyak 96 responden setara $56.5 \%$ yang berusia 21 25 tahun, sebanyak 6 responden setara 3.5\% yang berusia 26-30 tahun, sebanyak 5 responden setara $2.9 \%$ berusia 31-35 tahun, dan sebanyak 29 responden setara $17.1 \%$ berusia $\geq 36$ tahun. Berdasarkan metode pembelian, sebanyak 35 responden setara $20.6 \%$ menggunakan metode go food, sebanyak 50 responden $29.4 \%$ menggunakan metode grab food, sebanyak 85 responden setara 50\% menggunakan metode secara langsung.

\section{Model Pengukuran}

Siregar (2012) menyatakan bahwa kesahihan atau validitas merupakan uji yang menunjukkan sejauh mana suatu alat ukur dapat mengukur apa yang akan diukur. Nisfiannoor (2013) mengatakan bahwa untuk menyimpulkan dan menilai butir dalam suatu kuesioner tersebut valid atau tidak valid adalah apabila nilai $R$ tabel lebih besar dari 0.2, maka dengan itu item tersebut dapat dinyatakan valid, namun apabila dibawah dari angka 0.2 atau bertanda negatif maka butir tersebut dinyatakan tidak valid atau gugur. Seluruh indikator dalam penelitian ini dinyatakan valid karena memiliki nilai diatas 0.2 .

Tabel 1 Uji Validitas

\begin{tabular}{llcc}
\hline \multirow{2}{*}{ Variabel } & \multicolumn{1}{c}{ Butir Indikator } & $\begin{array}{c}\text { Corrected } \\
\text { Item Total } \\
\text { Correlation }\end{array}$ & Keterangan \\
& $\begin{array}{l}\text { Saya merasa percaya dengan merek } \\
\text { pilihan celebrity endorser. }\end{array}$ & 0.680 & Valid \\
\hline $\begin{array}{l}\text { Selebrity } \\
\text { Endorsement }\end{array}$ & $\begin{array}{l}\text { Saya merasa celebrity endorser dapat } \\
\text { dipercaya. }\end{array}$ & 0.625 & Valid \\
\cline { 2 - 4 } & $\begin{array}{l}\text { Saya menganggap review dari } \\
\text { celebrity endorser itu jujur. }\end{array}$ & 0.610 & Valid \\
\cline { 2 - 4 } & $\begin{array}{l}\text { Saya merasa celebrity endorser } \\
\text { memiliki pengetahuan lebih tentang } \\
\text { Fore Coffee. }\end{array}$ & 0.606 & Valid \\
\cline { 2 - 4 } & $\begin{array}{l}\text { Saya percaya celebrity endorser ahli } \\
\text { dalam bidangnya. }\end{array}$ & 0.550 & Valid \\
\cline { 2 - 4 } & $\begin{array}{l}\text { Saya merasa celebrity endorser } \\
\text { memiliki daya tarik yang kuat. }\end{array}$ & 0.440 & Valid \\
\cline { 2 - 4 } & Saya merasa celebrity endorser & 0.379 & Valid \\
\hline
\end{tabular}




\begin{tabular}{|c|c|c|c|}
\hline & \multicolumn{3}{|l|}{ memiliki penampilan yang menarik. } \\
\hline & $\begin{array}{l}\text { Saya merasa tertarik saat melihat } \\
\text { celebrity endorser. }\end{array}$ & 0.667 & Valid \\
\hline & $\begin{array}{l}\text { Saya merasa memiliki gaya hidup } \\
\text { yang mirip dengan celebrity } \\
\text { endorser. }\end{array}$ & 0.537 & Valid \\
\hline & $\begin{array}{l}\text { Saya memiliki kesukaan yang sama } \\
\text { dengan celebrity endorser. }\end{array}$ & 0.637 & Valid \\
\hline & $\begin{array}{l}\text { Saya menyukai perilaku dari } \\
\text { celebrity endorser Fore Coffee. }\end{array}$ & 0.620 & Valid \\
\hline & $\begin{array}{l}\text { Saya tertarik dengan gaya/style } \\
\text { celebrity endorser. }\end{array}$ & 0.604 & Valid \\
\hline & $\begin{array}{l}\text { Saya sering melihat Celebrity } \\
\text { endorser di Instagram. }\end{array}$ & 0.402 & Valid \\
\hline & $\begin{array}{l}\text { Saya mengetahui celebrity endorser } \\
\text { yang mempromosikan Fore Coffee. }\end{array}$ & 0.608 & Valid \\
\hline & $\begin{array}{l}\text { Celebrity endorser yang digunakan } \\
\text { cocok dengan merek Fore Coffee. }\end{array}$ & 0.741 & Valid \\
\hline & $\begin{array}{l}\text { Saya percaya celebrity endorser } \\
\text { menggunakan produk Fore Coffee. }\end{array}$ & 0.625 & Valid \\
\hline \multirow{8}{*}{$\begin{array}{l}\text { Perceived } \\
\text { Advertising } \\
\text { Value }\end{array}$} & $\begin{array}{l}\text { Saya percaya terhadap iklan Fore } \\
\text { Coffee. }\end{array}$ & 0.592 & Valid \\
\hline & $\begin{array}{l}\text { Saya memanfaatkan iklan sebagai } \\
\text { referensi untuk membeli produk Fore } \\
\text { Coffee. }\end{array}$ & 0.480 & Valid \\
\hline & $\begin{array}{l}\text { Saya tidak merasa terganggu saat } \\
\text { melihat iklan Fore Coffee. }\end{array}$ & 0.588 & Valid \\
\hline & $\begin{array}{l}\text { Saya tidak merasa kesal saat melihat } \\
\text { iklan Fore Coffee. }\end{array}$ & 0.560 & Valid \\
\hline & $\begin{array}{l}\text { Iklan Fore Coffee memberikan } \\
\text { informasi yang saya butuhkan. }\end{array}$ & 0.672 & Valid \\
\hline & $\begin{array}{l}\text { Saya mendapatkan informasi } \\
\text { mengenai promo dari iklan Fore } \\
\text { Coffee. }\end{array}$ & 0.419 & Valid \\
\hline & $\begin{array}{l}\text { Saya merasa terhibur saat melihat } \\
\text { iklan Fore Coffee. }\end{array}$ & 0.594 & Valid \\
\hline & $\begin{array}{l}\text { Saya menikmati saat melihat iklan } \\
\text { Fore Coffee. }\end{array}$ & 0.709 & Valid \\
\hline \multirow{6}{*}{$\begin{array}{l}\text { Keputusan } \\
\text { Pembelian }\end{array}$} & $\begin{array}{l}\text { Saya merasa Fore Coffee sudah } \\
\text { menjadi kebutuhan saya. }\end{array}$ & 0.509 & Valid \\
\hline & $\begin{array}{l}\text { Saya merasa iklan Fore Coffee } \\
\text { memberikan informasi mengenai } \\
\text { promo sesuai dengan kebutuhan } \\
\text { saya. }\end{array}$ & 0.582 & Valid \\
\hline & $\begin{array}{l}\text { Saya merasa mudah mencari } \\
\text { informasi mengenai Fore Coffee di } \\
\text { Instagram. }\end{array}$ & 0.443 & Valid \\
\hline & $\begin{array}{l}\text { Fore Coffee menyediakan informasi } \\
\text { yang cukup lengkap. }\end{array}$ & 0.598 & Valid \\
\hline & $\begin{array}{l}\text { Fore Coffee merupakan alternatif } \\
\text { pertama saya saat ingin membeli } \\
\text { minuman kopi. }\end{array}$ & 0.468 & Valid \\
\hline & Saya memilih Fore Coffee karena & 0.558 & Valid \\
\hline
\end{tabular}




\begin{tabular}{lcc}
$\begin{array}{l}\text { memiliki promo yang menarik } \\
\text { dibandingkan merek lainnya }\end{array}$ & \\
\hline $\begin{array}{l}\text { Saya melakukan pembelian di Fore } \\
\text { Coffee atas pengaruh dari } \\
\text { iklan/promo. }\end{array}$ & 0.474 & Valid \\
\hline $\begin{array}{l}\text { Saya merasa Celebrity endorser } \\
\text { membuat saya tertarik untuk } \\
\text { membeli di Fore Coffee. }\end{array}$ & 0.555 & Valid \\
\hline $\begin{array}{l}\text { Saya puas atas pembelian yang saya } \\
\text { lakukan di Fore Coffee. }\end{array}$ & 0.652 & Valid \\
\hline $\begin{array}{l}\text { Saya akan melakukan pembelian } \\
\text { ulang di Fore Coffee. }\end{array}$ & 0.532 & Valid \\
\hline
\end{tabular}

Sumber: Data primer, diolah dengan SPSS 15

Realibilitas merupakan cara agar mengetahui hasil pengukuran dapat tetap konsisten, apabila dilakukan kembali pengukuran dua kali atau lebih terhadap masalah yang serupa dengan menggunakan alat pengukuran yang sama (Siregar, 2013). Ghozali (2006) mengatakan suatu instrumen dalam penelitian dapat dinyatakan reliable apabila memiliki nilai Cronbach's Alpha lebih dari 0.6 dan bila nilai Cronbach's Alpha suatu instrumen kurang dari 0.6 maka tidak reliable.

Tabel 2 Uji Realibilitas

\begin{tabular}{lcl}
\hline \multicolumn{1}{c}{ Variabel } & Cronbach's Alpha & Keterangan \\
\hline Celebrity Endorsement & 0.905 & Reliable \\
\hline Perceived Advertising Value & 0.842 & Reliable \\
\hline Keputusan Pembelian & 0.837 & Reliable \\
\hline
\end{tabular}

Sumber: Data primer, diolah dengan SPSS 15

Tabel 3 Hasil Pengujian Hipotesis

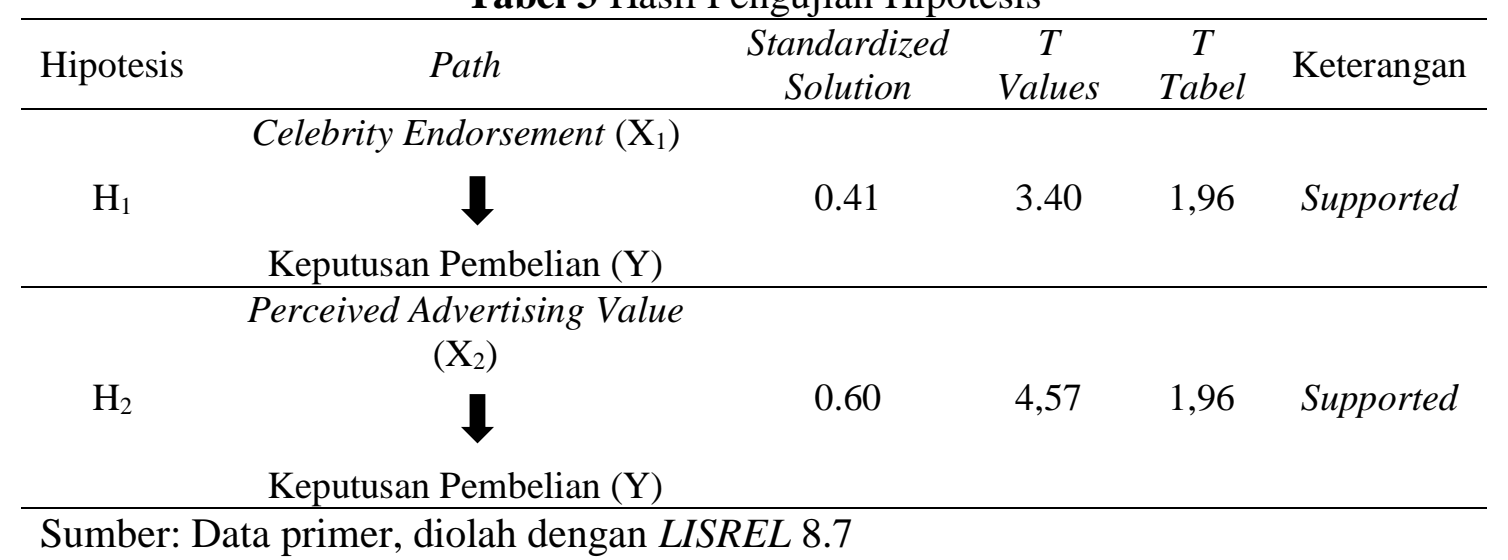

\section{Diskusi}

Menurut hasil yang diterima dari tabel 3 hasil pengujian hipotesis dapat diketahui bahwa perceived advertising value memberikan pengaruh yang lebih tinggi daripada celebrity endorsement. Oleh sebab itu, untuk tetap membangun dan mempengaruhi keputusan pembelian konsumen, perusahaan Fore Coffee perlu terus memperbaharui dan menambah kualitas iklan yang ditampilkan agar para konsumen menikmati iklan tersebut saat ditampilkan. Hasil penelitian ini sejalan dengan penelitian terdahulu yang telah dilakukan oleh Gaber et al., (2019) bahwa dimensi- 
dimensi dari variabel perceived advertising value memiliki pengaruh positif terdahap keputusan pembelian.

Celebrity endorsement memberikan pengaruh terhadap keputusan pembelian yang dilakukan oleh konsumen, dalam penelitian ini menunjukkan bahwa semakin cocok pemilihan celebrity endorser yang dilakukan oleh Fore Coffee, maka akan meningkatkan tingkat keputusan pembelian konsumen. Oleh sebab itu, untuk tetap membangun dan mempengaruhi keputusan pembelian konsumen, perusahaan Fore Coffee harus tetap menjaga dan mencari celebrity endorser yang cocok/match-up antara seorang endorser dan merk Fore Coffee karena hal tersebut yang memiliki pengaruh paling signifikan dalam variabel celebrity endorsement. Hasil penelitian ini sejalan dengan penelitian terdahulu yang telah dilakukan dan memperoleh hasil dimana dimensi tersebut memiliki nilai tertinggi yang mempengaruhi keputusan pembelian (Ha dan Lam, 2017).

\section{Simpulan}

Maka dari hasil yang didapat tersebut penulis memberikan beberapa kesimpulan. Kesimpulannya sebagai berikut:

1. Celebrity endorsement memiliki pengaruh positif dan signifikan terhadap keputusan pembelian konsumen dalam Fore Coffee.

2. Perceived advertising value memiliki pengaruh positif dan signifikan terhadap keputusan pembelian konsumen dalam Fore Coffee.

\section{Ucapan Terima Kasih}

Dengan tulus penulis mengucapkan terima kasih kepada Viola, Sisca, Charlie dan seluruh pihak yang telah membantu dalam penelitian ini, memberikan dukungan dan berkontribusi dalam hal apapun hingga terselesaikannya penelitian ini.

\section{Daftar Pustaka}

Adam \& Hussein, (2017). "Impact of Celebrity Endorsement On Consumers Buying Behavior”. British Journal of Marketing Studies, 5, 79-121.

Ammarie \& Nurfebiaraning. (2018). "Pengaruh Iklan Pop-Up Bukalapak Versi Pahlawan Pada Youtube Terhadap Sikap Khalayak". Jurnal Manajemen Komunikasi, 2, 78-94.

Balawera, Asrianto. (2013). “Green Marketing dan Corporate Social Responsibility Pengaruhnya Terhadap Keputusan Pembelian Konsumen Melalui Minat Membeli Produk Organik di Freshmart Kota Manado". Jurnal EMBA, 1, 2117-2129.

Brackett \& Carr, (2001). "Cyberspace advertising vs other media: Consumer vs. mature student attitudes". Journal of Advertising Research, 5, 23-32.

Dennyka \& Rezi Erdiansyah. (2017). "Pengaruh Daya Tarik Iklan Mobile Legends di Youtube Terhadap Keputusan Pembelian Karakter Game Mobile Legends". Proligia, 1, 345-350.

Ducoffe, Robert H, (1996). "Advertising Value and Advertising On The Web". Journal of Advertising Research, 21-32.

Gaber, Wright \& Kooli (2019). "Consumer Attitudes towards Instagram Advertisements in Egypt: The Role of the Perceived Advertising Value and Personalization”. Cogent Business \& Management, 6, 1-13. 
Ghozali, Imam. (2013). Aplikasi Analisis Multivariate dengan Program IBM SPSS 21 Update PLS Regresi. Semarang: Badan Penerbit Universitas Diponegoro.

Ha \& Lam, (2017). "The Effects of Celebrity Endorsement on Customer's Attitude toward Brand and Purchase Intention". International Journal of Economics and Finance, 9, 64-77.

Khan \& Lodhi, (2016). "Influence Of Celebrity Endorserment On Consumer Purchase Decision : A Case Of Karachi". Imperial Journal of Interdisciplinary Research (IJIR), 2,102-111.

Kotler, dan Keller, (2012). Manajemen Pemasaran. Edisi 12. Jakarta: Erlangga.

Mulyana dan Priccila. (2014). "Pengaruh Periklanan Dan Promosi Penjualan Terhadap Keputusan Pembelian”. Jurnal Ilmilah Manajemen Kesatuan, 2, 119-128.

Mulyawati, Kumadji, dan Kusumawati. (2015). "Pengaruh Celebrity Endorser Terhadap Sikap Konsumen Serta Dampaknya Pada Keputusan Pembelian (Survei pada Mahasiswi Fakultas Ilmu Administrasi Universitas Brawijaya Angkatan 2013 dan 2014 Pengguna Produk Perawatan Wajah Merek Garnier)". Jurnal Administrasi Bisnis (JAB), 24, 1-6.

Nisfiannoor, Muhammad. (2009). Pendekatan Statistik Modern. Jakarta: Salemba Huamanika.

Siregar, Syofian. (2012). Metode Penelitian Kuantitatif Dilengkapi Dengan Perbandingan Perhitungan Manual dan SPSS. Jakarta : Prenadamedia Group.

Sugiyono. (2016). Metode Penelitian Kuantitatif, Kualitatif dan R\&D. Bandung: PT Alfabet.

Suhandang, Kustadi. (2010). Periklanan : Manajemen, Kiat dan Strategi. Bandung : Nuansa

Watie. (2012). "Periklanan Dalam Media Baru". The Messenger, 4, 37-42.

Wijayanti, Ratna. 2008. "Analisis Faktor yang Mempengaruhi Keputusan Pembelian Konsumen terhadap Pembersih Wajah Ovale". Jurnal Aplikasi Manajemen. Volume 6. Nomor 2. Agustus. Hal. 138 - 154. Banjarmasin. Universitas Achmad Yani.

Zeng, Zuohao, Rong dan Zhilin. (2009). "Determinants of online service satisfaction and their impacts onbehavioural intention". Total Quality Management. Vol. 20, No. 9, 953-969. 